\title{
Neu Differentiation Factor Upregulates Epidermal Migration and Integrin Expression in Excisional Wounds
}

\author{
Dimitry M. Danilenko, * Brian D. Ring, * John Z. Lu, * John E. Tarpley, " David Chang, \\ and Glenn F. Pierce* \\ Departments of * Experimental Pathology, ${ }^{\ddagger}$ Immunology, ${ }^{8}$ Recovery Process Development, and "Mammalian Cell Molecular Biology, \\ Amgen, Inc., Thousand Oaks, California 91320-1789
}

\begin{abstract}
Neu differentiation factor (NDF) is a 44-kD glycoprotein which was isolated from ras-transformed rat fibroblasts and indirectly induces tyrosine phosphorylation of the HER-2/ neu receptor via binding to either the HER-3 or HER-4 receptor. NDF contains a receptor binding epidermal growth factor (EGF)-like domain and is a member of the EGF family. There are multiple different isoforms of NDF which arise by alternative splicing of a single gene. To date, in vivo biologic activities have not been demonstrated for any NDF isoform. Since NDF, HER-2/neu, and HER-3 are present in skin, and other EGF family members can influence wound keratinocytes in vivo, we investigated whether NDF would stimulate epidermal migration and proliferation in a rabbit ear model of excisional wound repair. In this model, recombinant human NDF- $\alpha_{2}$ (rhNDF- $\left.\alpha_{2}\right)$, applied once at the time of wounding, induced a highly significant increase in both epidermal migration and epidermal thickness at doses ranging from 4 to $40 \mu \mathrm{g} / \mathrm{cm}^{2}$. In contrast, rhNDF- $\alpha_{1}$, rhNDF- $\beta_{1}$, and rhNDF- $\beta_{2}$ had no apparent biologic effects in this model. rhNDF- $\alpha_{2}$ also induced increased neoepidermal expression of $\alpha_{5}$ and $\alpha_{6}$ integrins, two of the earliest integrins to appear during epidermal migration. In addition, rhNDF- $\alpha_{2}$-treated wounds exhibited increased neoepidermal expression of cytokeratin 10 and filaggrin, both epidermal differentiation markers. NDF $\alpha$ isoforms were expressed in dermal fibroblasts of wounded and unwounded skin, while both HER-2/neu and HER-3 were expressed in unwounded epidermis and dermal adnexa. In wounds, HER-2/neu expression was markedly decreased in the wound neoepidermis while neoepidermal HER-3 expression was markedly upregulated. Taken together, these results suggest that endogenous NDF- $\alpha_{2}$ may function as a paracrine mediator directing initial epidermal migration during cutaneous tissue repair. (J. Clin. Invest. 1995.
\end{abstract}

A portion of this work was published in abstract form (1994. FASEB [Fed. Am. Soc. Exp. Biol.] J. 8:535a).

Address correspondence to Dimitry M. Danilenko, D.V.M., Ph.D., Department of Experimental Pathology, MS 15-2-A-226, Amgen, Inc., 1840 DeHavilland Drive, Thousand Oaks, CA 91320-1789. Phone: 805447-6809; FAX: 805-447-1939. Glenn F. Pierce's present address is Department of Preclinical Sciences, PRIZM Pharmaceuticals, 11035 Roselle Street, San Diego, CA 92121.

Received for publication 15 April 1994 and in revised form 4 October 1994.

J. Clin. Invest.

(c) The American Society for Clinical Investigation, Inc 0021-9738/95/02/0842/10 \$2.00

Volume 95, February 1995, 842-851
95:842-851.) Key words: adhesion molecules - growth factors • immunohistochemistry • keratinocytes • wound healing

\section{Introduction}

Neu differentiation factor (NDF) ${ }^{1}$ is a $44-\mathrm{kD}$ glycoprotein which was isolated from ras-transformed rat fibroblasts and was shown to induce tyrosine phosphorylation of the HER-2/neu receptor on several human mammary adenocarcinoma cell lines $(1,2)$. A human homologue of NDF, termed heregulin, was independently isolated from conditioned medium of MDA-MB231 human mammary carcinoma cells and was shown to induce tyrosine phosphorylation of the HER-2/neu receptor in MCF7 human mammary carcinoma cells (3). When NDF/heregulin was originally identified, it was believed to be the specific ligand for the HER-2/neu receptor. More recent studies have shown, however, that two recently isolated members of the epidermal growth factor receptor (EGFR) family, HER-3 and HER-4 (46 ), are the actual specific receptors for NDF/heregulin (7-9) and that HER-2/neu is tyrosine phosphorylated through activation of either the HER-3 or HER-4 receptor by NDF/heregulin (7-9).

NDF is a member of the EGF family of growth factors, a family which includes transforming growth factor- $\alpha$ (TGF- $\alpha$ ), amphiregulin, betacellulin, heparin-binding EGF-like growth factor, and vaccinia virus growth factor (10-14). Within the EGF growth factor family, only NDF has been shown to activate HER-2/neu $(1,2)$. In addition, NDF does not bind to EGFR $(1,3)$, while all other known EGF family members bind EGFR $(13,15)$.

There are at least six distinct NDF precursor proteins (proNDFs), which are identical in their first 213 amino acid residues. This 213-amino acid stretch includes a basic $\mathrm{NH}_{2}$ terminus which is proteolytically cleaved at amino acid 14 in naturally occurring rat NDF, an immunoglobulin-like domain, a spacer domain, and two disulfide loops of a receptor binding EGF-like domain (16). These proNDFs give rise to at least 12 different isoforms of NDF which arise by alternative splicing of a single NDF gene (16). Isoform structural variation arises in three domains which $\mathrm{COOH}$-terminally flank the identical 213 amino acid residues (16). The first variable domain is a $\mathrm{COOH}$-terminal portion of the receptor binding EGF-like domain and distinguishes $\alpha$ and $\beta$ isoforms. An adjacent juxtamembrane region of the EGF-like domain is the second variable

1. Abbreviations used in this paper: bFGF, basic fibroblast growth factor; BrdU, bromodeoxyuridine; CK, cytokeratin; EGFR, EGF receptor; $H \& E$, hematoxylin and eosin; NDF, neu differentiation factor; proNDF, NDF precursor proteins; rh, recombinant human. 


\section{pro NDF}

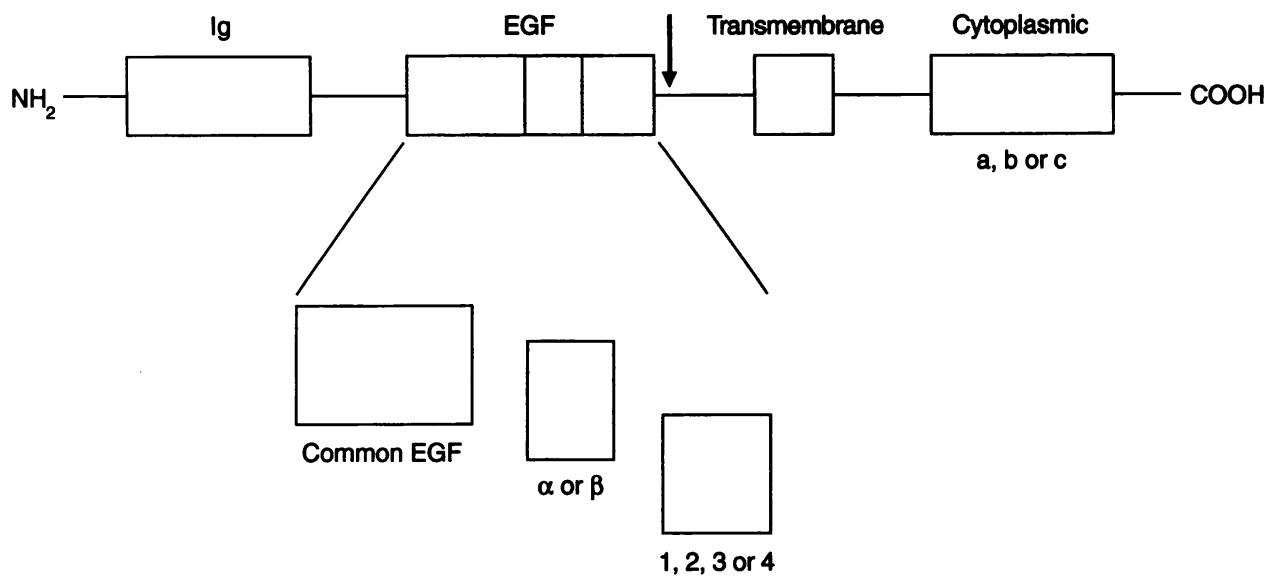

Figure 1. Schematic diagram of a proNDF molecule illustrating the three variably spliced domains (EGF $\alpha$ or $\beta$, EGF juxtamembrane, and cytoplasmic) which give rise to the different NDF isoforms. The arrow indicates the putative extramembrane cleavage site.

domain and gives rise to isoforms 1-4. Lastly, variability in the length of the cytoplasmic tail determines isoforms $a, b$, and c (16) (Fig. 1).

Some NDF isoforms display partial tissue specificity. ProNDF- $\alpha_{2}$ is the predominant isoform in mesenchymal cells, including fibroblasts, while proNDF- $\beta_{1}$ is the major isoform in nervous tissue (16). Several other NDF isoforms were originally cloned from nervous tissue and later were found to represent splice variants of NDF. These molecules include a group of Schwann cell mitogens collectively termed glial growth factors (17) and a factor, termed acetylcholine receptor inducing activity (ARIA), which stimulates acetylcholine receptor synthesis at the neuromuscular junction (18).

Although the HER-2/neu receptor is not the specific receptor for NDF, NDF's biologic effects are mediated through tyrosine phosphorylation of HER-2/neu via HER-3 and HER-4 tyrosine phosphorylation in cells which coexpress both receptors $(7,9)$. Both HER-2/neu and HER-3 are distributed over a relatively wide range of epithelial tissues, including the skin (19-21), while precise tissue localization of HER-4 has not yet been done. Immunohistochemical studies have localized both HER-2/neu and HER-3 to the basal and suprabasal layers of the epidermis $(19,21,22)$, as well as to epidermal adnexa $(20,21)$. NDF has been shown to be expressed in the skin of embryonic mice by in situ hybridization, although the specific cell type could not be discerned (23). The coexpression of NDF and both the HER-2/neu and HER-3 receptors in the skin, coupled with the ability of NDF to arrest proliferation and induce differentiation in a human breast carcinoma cell line overexpressing HER-2/neu (1), suggests that the interaction of NDF with the HER-2/neu-HER-3 receptor complex may play an important role in the regulation of normal epidermal growth and differentiation.

To date, in vivo biologic activities have not yet been demonstrated for NDF, but EGF, TGF- $\alpha$, and vaccinia virus growth factor have all been shown to variably stimulate in vivo wound reepithelialization (24-27). Since NDF is structurally related to these three growth factors, but stimulates a distinct receptor, we sought to investigate whether NDF would influence epidermal migration in an in vivo model of excisional deep partial thickness wound repair. We chose to first use the NDF- $\alpha_{2}$ isoform, since this isoform is the predominant isoform in mesen- chymal cells and had been localized to the skin $(16,23)$, and then to compare the effects obtained using the NDF- $\alpha_{2}$ isoform with the effects observed with other NDF isoforms.

\section{Methods}

Recombinant NDF. Recombinant human NDF- $\alpha_{2}$ 14-241 (rhNDF- $\alpha_{2}$ ), rhNDF- $\alpha_{1} 14-249$, rhNDF- $\beta_{1}$ 14-246, and rhNDF- $\beta_{2}$ 14-238 were each produced in Escherichia coli, refolded, and purified to homogeneity by conventional techniques, and tested endotoxin free. Each isoform was determined to have bioactivity by its ability to induce tyrosine phosphorylation of p185 $5^{\text {neu }}$ in MDA-MB453 human breast carcinoma cells at concentrations as low as $1 \mathrm{ng} / \mathrm{ml}(22 \mathrm{pM})(1)$, which was equivalent to the bioactivity of Chinese hamster ovary cell-derived rat NDF- $\alpha_{2}$ (16).

Rabbit ear excisional wound model. Female, New Zealand White rabbits (3.5-4.0 kg) (Western Oregon Rabbit Co., Philomath, OR) were used for all experiments. The rabbit full thickness dermal wound model (27) was modified by removing cartilage in addition to the overlying epidermis and dermis (Fig. 2). In this model, the wound heals by sprouting of adnexa from the opposite side of the ear as well as by migration of epidermal keratinocytes from the wound margins (28). A 6-mm trephine was used to aseptically create four $0.25-\mathrm{cm}^{2}$ wounds on each ear. Immediately after wounding of both ears, $5 \mu \mathrm{l}$ of rhNDF- $\alpha_{2}$ at specified concentrations in phosphate-buffered saline (PBS), or $5 \mu \mathrm{l}$ of PBS alone (vehicle control), was placed within the wound bed, and the wounds were covered with Tegaderm occlusive dressing (3M Microbiology Products, St. Paul, MN). $30 \mathrm{~h}$ and 3, 4, or $5 \mathrm{~d}$ after wounding, the rabbits were killed, and all wounds were excised from the ears. Each wound was bisected with one half fixed in Omnifix II (Al-Con Genetics, Inc., Melville, NY) for routine histologic evaluation and the other half embedded in OCT media (Miles Inc., Elkhart, IN) and snap frozen in isopentane chilled to its freezing point in liquid nitrogen for integrin, NDF, and HER-2/neu immunohistochemical staining.

Assessment of reepithelialization and wound healing. $3-\mu \mathrm{m}$ thick, hematoxylin and eosin (H\&E)-stained sections of each wound were assessed for reepithelialization and epithelial thickness using several different measurements (Fig. 2). The epithelial gap (EG) is a linear measurement taken between the tongues of migrating new epithelium from each wound margin. The cartilage gap (CG) is the diameter of the wound measured between the cartilage plates at each margin. Both of these measurements were done with a calibrated ocular micrometer using the $4 \times$ objective on a Nikon Optiphot microscope. The new epithelium (NE) was derived by subtracting the EG from the CG, thus 


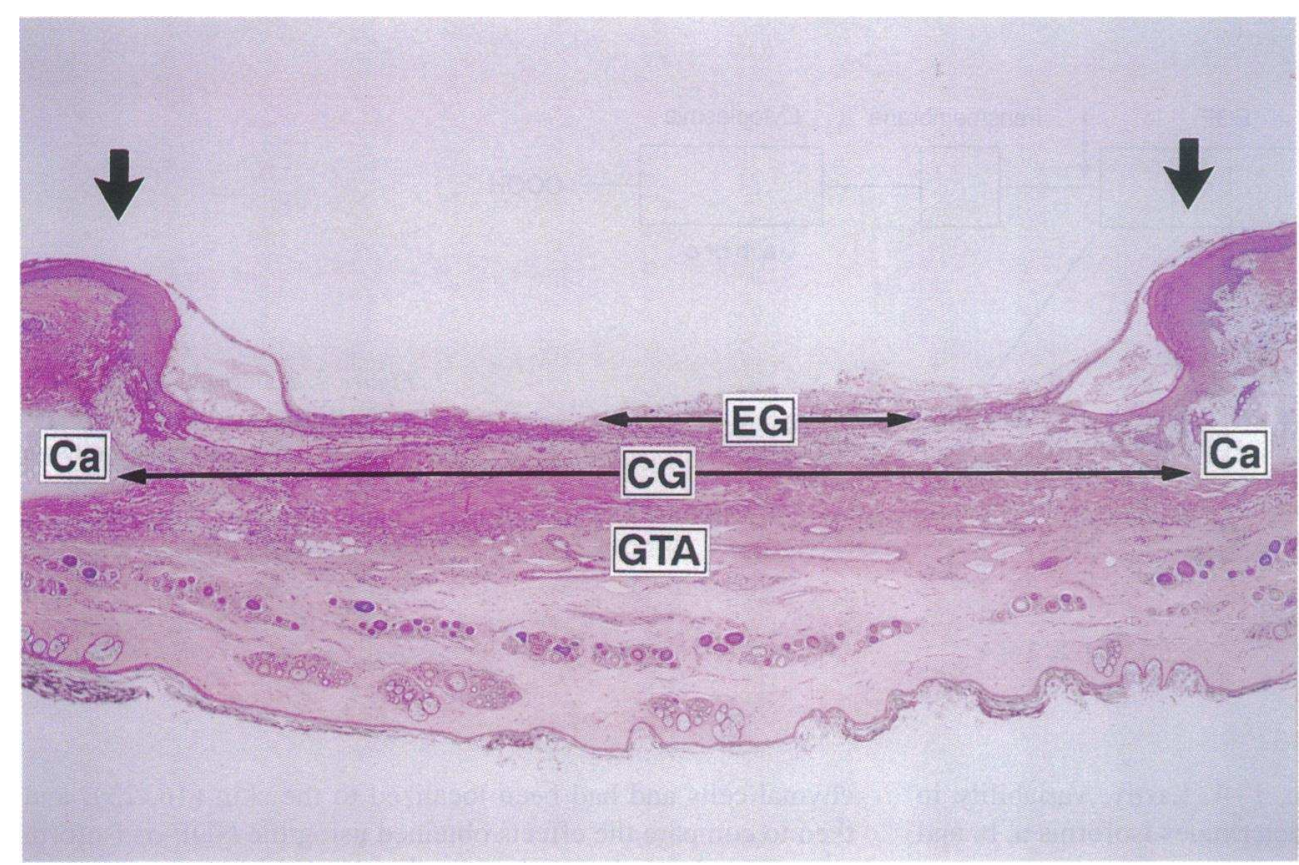

Figure 2. H\&E-stained histologic section of the modified rabbit ear partial thickness excisional wound model. Original magnification, $\times 4$. Bold arrows indicate wound margins. $C a$, cartilage plate; $C G$, cartilage gap; $E G$, epithelial gap; GTA, granulation tissue area. standardizing any variability which might have been present in wound diameter. The epithelial area is a measurement of all the epithelium that has migrated into the wound bed from each cartilage margin inward and was measured via a calibrated Quantimet 520 image analyzer (Leica Inc., Deerfield, IL) coupled to a Nikon Optiphot microscope. For assessment of possible rhNDF effects on dermal cellular components, the granulation tissue area (GTA), a measurement of all wound bed tissue exclusive of epithelium, was also done on a Quantimet 520 image analyzer. All wound measurements were sorted by dose, and each dose was analyzed versus the vehicle control using one way analysis of variance (two-tailed) coupled with the Bonferonni/Dunn post-hoc test at a 5\% significance level (Statview 4.0; Abacus Concepts, Inc., Berkeley, CA). Results are reported as mean \pm the standard error.

Assessment of proliferation using anti-bromodeoxyuridine (BrdU). $30 \mathrm{~min}$ before wound harvest, each rabbit was injected intravenously with $50 \mathrm{mg} / \mathrm{kg}$ body wt of BrdU (Aldrich Chemical Co., Milwaukee, WI). BrdU in wound sections was detected by avidin-biotin complex immunoperoxidase staining using an anti-BrdU monoclonal antibody (Dako Corp., Carpinteria, CA) (28). Assessment of keratinocyte BrdU labeling was done by a blinded observer with an ocular micrometer using the $20 \times$ objective. Labeled and unlabeled keratinocytes in both basal and suprabasal compartments were counted from the tip of each new epithelial tongue a distance of $1.5 \mathrm{~mm}$ toward the wound margin ( $3 \mathrm{~mm}$ total). Unpaired, two-tailed Student's $t$ tests at a 5\% significance level on Statview 4.0 were used to compare treated versus control wounds, and results are reported as mean percent labeled keratinocytes\pm the standard error.

Immunohistochemical analysis and monoclonal antibody characterization. Omni-fixed, paraffin-embedded, 3- $\mu$ m-thick wound sections were used for analysis of filaggrin, cytokeratins 10 and 14, and HER3 expression. Expression of the three keratinocyte differentiation markers was detected by avidin-biotin complex immunoperoxidase staining (28) using mAbs directed against human filaggrin (Biomedical Technologies, Inc., Stoughton, MA), human cytokeratin 10 (clone DE-K10; Dako Corp.), and human cytokeratin 14 (clone LL002; BioGenex Labs, San Ramon, CA). HER-3 expression was detected by a specific antihuman HER-3 mAb (clone RTJ.1, mouse IgM; Santa Cruz Biomedical, Santa Cruz, CA) using avidin-biotin complex immunoperoxidase as described previously (28), but with substitution of a biotinylated goat anti-mouse IgM secondary (Jackson ImmunoResearch Laboratories, Inc., West Grove, PA). Because of high background staining in wound beds, HER-3-stained sections were also avidin-biotin blocked (Vector Labs, Inc., Burlingame, CA). Expression of integrins, NDF, and HER$2 /$ neu was also detected by avidin-biotin complex immunoperoxidase as above, but staining was done on $5-\mu \mathrm{m}$-thick frozen sections of wounds. The $\alpha_{2}$ integrin was detected with a mouse anti-human $\alpha_{2}$ integrin mAb (clone P1E6; GIBCO BRL, Grand Island, NY), $\alpha_{5}$ integrin was detected with a mouse anti-human $\alpha_{5}$ integrin $\mathrm{mAb}$ (clone P1D6; Dako Corp.), and $\alpha_{6}$ integrin was detected with a rat anti-human $\alpha_{6}$ integrin mAb (clone GoH3; Amac, Inc., Westbrook, ME). A mouse anti-human $\alpha_{3}$ integrin mAb (clone P1B5; Dako Corp.) was used to detect $\alpha_{3}$ integrin but did not specifically stain rabbit tissues.

NDF was detected by two different anti-NDF mAbs produced by the authors. Anti-NDF mAbs were characterized using a BIAcore instrument (Pharmacia Biosensor, Uppsala, Sweden), which detects real-time biospecific interactions based on changes in optical properties at the surface of a sensor chip $(29,30)$ (data not shown), as well as by ELISA (data not shown) and slot blot analysis (Fig. 3). One anti-NDF mAb, 1H7A (mouse IgG2b), recognized only $\alpha$ isoforms of NDF and exhibited no reactivity with NDF $\beta$ isoforms. The other anti-NDF mAb, $1 \mathrm{H} 8 \mathrm{C}$ (mouse IgG2b), recognized both $\alpha$ and $\beta$ NDF isoforms. Neither

\section{Clone: 1H7A 1H8C No Antibody}

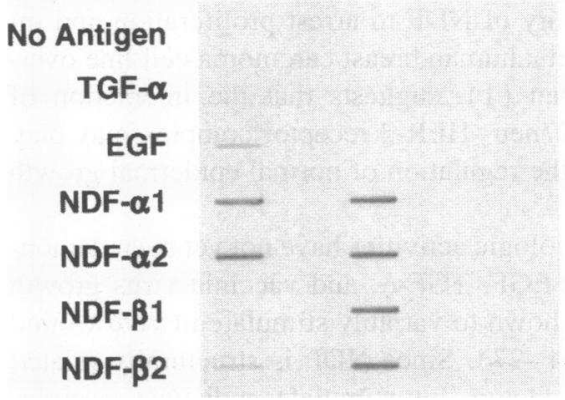

Figure 3. Slot blot reactivity of anti-NDF mAbs $1 \mathrm{H} 7 \mathrm{~A}$ and $1 \mathrm{H} 8 \mathrm{C}$, illustrating that mAb 1H7A only reacts with $\alpha$ isoforms of NDF, mAb $1 \mathrm{H} 8 \mathrm{C}$ reacts with both $\alpha$ and $\beta$ isoforms of NDF, and neither mAb cross-reacts with EGF or TGF- $\alpha$. 


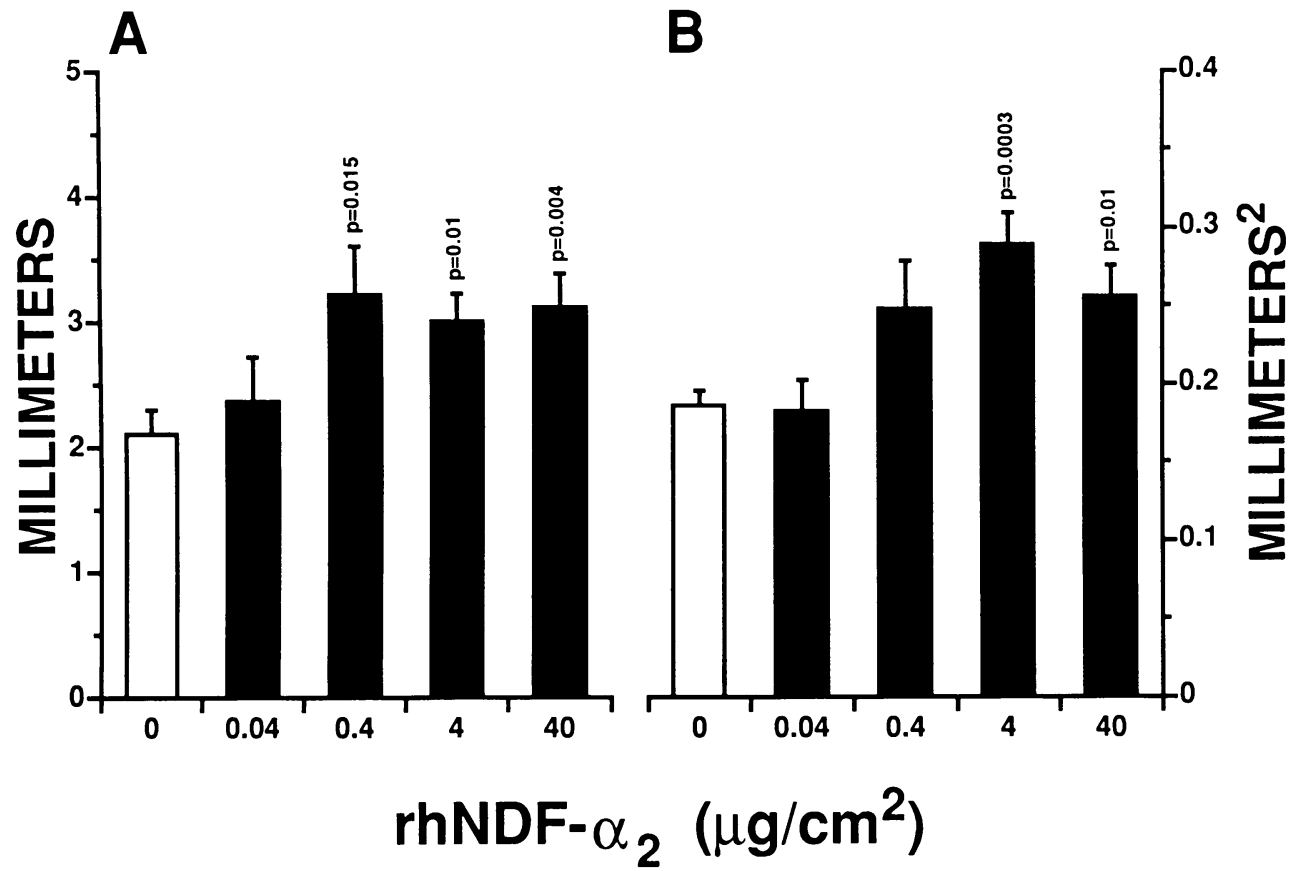

Figure 4. (A) 5-d reepithelialization in rhNDF- $\alpha_{2}$-treated wounds. There is a dose-dependent increase between 0 and 0.4 $\mu \mathrm{g} / \mathrm{cm}^{2}$ rhNDF- $\alpha_{2}$, with higher doses showing no further increase in epithelialization. $(B)$ 5-d epidermal thickness in rhNDF- $\alpha_{2}-$ treated wounds. There is a dosedependent increase between 0 and $4 \mu \mathrm{g} / \mathrm{cm}^{2}$ rhNDF- $\alpha_{2}$, with $40 \mu \mathrm{g} /$ $\mathrm{cm}^{2}$ exhibiting no further increase in epidermal thickness.
anti-NDF mAb exhibited any cross-reactivity with EGF or TGF- $\alpha$ (Fig. 3 ). HER-2/neu was detected by a specific anti-HER-2/neu mAb, clone HER 20 (mouse $\operatorname{IgG} 2 \mathrm{a}$ ), which was also produced and characterized using BIAcore and ELISA by the authors (data not shown).

Assessment of epidermal differentiation and integrin expression. Replicate paraffin-embedded and frozen sections of eight representative rhNDF- $\alpha_{2}$-treated wounds and eight control wounds were stained for filaggrin and cytokeratins 10 and 14 to assess epidermal differentiation and stained for $\alpha_{5}$ and $\alpha_{6}$ integrins to assess the extent of epidermal expression of these integrins. Slides were read, blinded, by a pathologist experienced in interpretation of immunohistochemical staining results (D. M. Danilenko), and subjectively evaluated on the intensity and extent of epidermal staining for each antigen evaluated. Each of the eight rhNDF- $\alpha_{2}$-treated wounds was then directly compared with the eight control wounds, and the number of rhNDF- $\alpha_{2}-$ treated wounds exhibiting either greater intensity or extent (depending on the antigen evaluated) than the control wound exhibiting the greatest staining for each particular antigen (e.g., 7/8) was reported.

\section{Results}

$r h N D F-\alpha_{2}$ increases reepithelialization and epidermal thickness. rhNDF- $\alpha_{2}$-treated wounds exhibited significantly increased reepithelialization (new epithelium) versus control wounds $5 \mathrm{~d}$ after wounding at doses ranging from 0.4 to 40 $\mu \mathrm{g} / \mathrm{cm}^{2}$ (Fig. $4 A$ ). There was a dose-dependent increase in reepithelialization between 0 and $0.4 \mu \mathrm{g} / \mathrm{cm}^{2}$, with higher doses not appreciably increasing reepithelialization. rhNDF- $\alpha_{2}-$ treated wounds also exhibited a significant increase in the thickness of new epithelium (epithelial area) $5 \mathrm{~d}$ after wounding at doses ranging from 4 to $40 \mu \mathrm{g} / \mathrm{cm}^{2}$, with a dose-dependent increase evident at doses of 0.04 to $4 \mu \mathrm{g} / \mathrm{cm}^{2}$ (Fig. $4 B$ ). rhNDF- $\alpha_{2}$ also significantly increased reepithelialization and new epithelial area $4 \mathrm{~d}$ after wounding at a dose of $4 \mu \mathrm{g}$ / $\mathrm{cm}^{2}$, the only dose tested (data not shown). In contrast to the epidermal effects induced by rhNDF- $\alpha_{2}$, the other NDF isoforms tested, rhNDF- $\alpha_{1}$, rhNDF- $\beta_{1}$, and $\operatorname{rhNDF}-\beta_{2}$, did not have any significant effects on reepithelialization or new epithe- lial area $5 \mathrm{~d}$ after wounding (data not shown). There was no difference in granulation tissue area in any of the rhNDF isoform-treated wounds versus control wounds, indicating that the rhNDF effect was epithelial specific (data not shown).

$r h N D F-\alpha_{2}$ does not significantly increase epidermal proliferation. The number of proliferating basal and suprabasal keratinocytes labeled with BrdU was counted at three different time points: $30 \mathrm{~h}, 3 \mathrm{~d}(72 \mathrm{~h})$, and $5 \mathrm{~d}(120 \mathrm{~h})$ after wounding. There were no statistically significant differences in proliferating basal and suprabasal keratinocytes in control wounds versus wounds treated with rhNDF- $\alpha_{2}$ at any of the three time points at all tested doses, although there was a trend toward increased proliferation in both basal and suprabasal keratinocytes in rhNDF$\alpha_{2}$-treated wounds $30 \mathrm{~h}$ after wounding (Table I).

rhNDF- $\alpha_{2}$-treated wounds exhibit increased neoepidermal expression of differentiation markers. Immunoperoxidase staining for filaggrin and cytokeratins (CK) 10 and 14 revealed that seven of eight rhNDF- $\alpha_{2}-$ treated wounds exhibited increased expression of filaggrin and CK10, both markers of epidermal terminal differentiation $(31,32)$, in the neoepidermis migrating across the wound bed when compared with control wounds. This increased expression of filaggrin and CK10 in rhNDF- $\alpha_{2}-$ treated wounds was largely confined to the oldest neoepidermis at the wound margins, although in some rhNDF- $\alpha_{2}-$ treated wounds (those nearly or fully reepithelialized) filaggrin was expressed in nearly all of the neoepidermis (Fig. 5, $C$ and $F$ ). CK14, a marker of basal keratinocytes (32), was expressed to the same extent in the regenerating epidermis of both rhNDF$\alpha_{2}$-treated and control wounds (Fig. 5, $G$ and $H$ ).

$r h N D F-\alpha_{2}$ upregulates epidermal integrin expression. Since rhNDF- $\alpha_{2}$ induced marked epidermal migration across the wound bed, and both EGF and TGF- $\alpha$ promote in vitro keratinocyte migration on collagen via increased keratinocyte expression of the collagen binding $\alpha_{2} \beta_{1}$ integrin (33), we investigated whether the accelerated migration induced by rhNDF- $\alpha_{2}$ might be due to increased epidermal integrin expression. In un- 
Table I. Proliferating Basal and Suprabasal Keratinocytes in rhNDF- $\alpha_{2}-$ treated Rabbit Ear Wounds versus Control Wounds

\begin{tabular}{lccr}
\hline & $30 \mathrm{~h}$ & $72 \mathrm{~h}$ & $120 \mathrm{~h}$ \\
\hline Basal keratinocytes & & & \\
$\quad$ Control & $11.91 \pm 5.20$ & $25.70 \pm 2.13$ & $28.00 \pm 1.57$ \\
$\quad$ rhNDF- $\alpha_{2}$ & $22.01 \pm 5.48$ & $20.93 \pm 3.00$ & $32.47 \pm 1.73$ \\
Suprabasal keratinocytes & & & \\
$\quad$ Control & $1.51 \pm 0.66$ & $4.39 \pm 1.27$ & $9.09 \pm 0.98$ \\
rhNDF- $\alpha_{2}$ & $3.90 \pm 0.98$ & $2.81 \pm 0.34$ & $11.38 \pm 1.10$ \\
\hline
\end{tabular}

Rabbits were injected intravenously with BrdU 30 min before harvest, and sections of wounds were immunohistochemically stained for BrdU. BrdU-labeled and unlabeled keratinocytes were counted by a blinded observer in both basal and suprabasal compartments a distance of 1.5 $\mathrm{mm}$ from the tip of each neoepidermal tongue toward the wound margin ( $3 \mathrm{~mm}$ total). Wounds treated with $4 \mu \mathrm{g}$ rhNDF- $\alpha_{2}$ per $\mathrm{cm}^{2}$ were compared with control wounds using unpaired, two-tailed Student's $t$ tests at a 5\% significance level. Results are reported as the mean percent BrdU-labeled keratinocytes \pm the standard error. There are no statistically significant differences between rhNDF- $\alpha_{2}$-treated versus control wounds at any time point, although there is a trend toward increased basal and suprabasal keratinocyte proliferation in 30-h rhNDF- $\alpha_{2}-$ treated wounds.

wounded skin, expression of $\alpha_{6}$ integrin, the $\alpha$ subunit of $\alpha_{6} \beta_{4}$ integrin, a receptor for laminin and possibly epiligrin $(34,35)$, was restricted to basal keratinocytes of the epidermis and adnexa. In the normal migrating epidermis covering the wound bed of 5-d-old control wounds, however, the distribution of $\alpha_{6}$ integrin increased to include most or all suprabasal keratinocytes. In seven of eight rhNDF- $\alpha_{2}$-treated wounds $5 \mathrm{~d}$ after wounding, the distribution of $\alpha_{6}$ integrin in the migrating new epidermis became even more widespread than it was in the new epidermis of control wounds (Fig. $6, A$ and $B$ ). $\alpha_{5}$ integrin, the $\alpha$ subunit of $\alpha_{5} \beta_{1}$ integrin, a fibronectin receptor (36), was not expressed at all in normal, unwounded epidermis, but was very weakly expressed in basal keratinocytes of the migrating new epidermis in some 5-d-old control wounds. In six of eight rhNDF- $\alpha_{2}$-treated wounds $5 \mathrm{~d}$ after wounding, $\alpha_{5}$ integrin was expressed on both basal and suprabasal keratinocytes and was more strongly expressed in the migrating epidermis than it was in control wounds, but the intensity of expression was not as pronounced as that observed with $\alpha_{6}$ integrin (Fig. 6, $C$ and D). $\alpha_{2}$ integrin, the $\alpha$ subunit of $\alpha_{2} \beta_{1}$ integrin, a receptor for type I and type IV collagen as well as epiligrin $(34,37)$, was expressed predominantly on endothelial cells and was expressed only very weakly on the basal epidermis in both rhNDF- $\alpha_{2}-$ treated and control wounds $5 \mathrm{~d}$ after wounding (not shown).

Expression of HER-2/neu, HER-3, and NDF epitopes in normal and wounded skin. HER-2/neu, as detected by $\mathrm{mAb}$ HER 20, and HER-3, as detected by mAb RTJ.1, were both expressed by epidermal and follicular keratinocytes, but exhibited markedly different levels of expression in wounded versus unwounded epidermis. HER-2/neu was expressed predominantly on keratinocytes in the basal cell layer and lower stratum spinosum of unwounded epidermis as well as in the basal epithelium of dermal adnexa (Fig. $7 \mathrm{~A}$ ). In migrating wound neoepidermis, HER-2/neu expression was markedly decreased as detected by decreased immunoperoxidase staining intensity in both rhNDF- $\alpha_{2}$-treated and control wounds (Fig. 7 B). HER-
3 was weakly expressed by basal keratinocytes in normal epidermis, but was strongly expressed by follicular keratinocytes in the hair bulb and inner root sheath as well as by follicular keratin (Fig. $7 C$ ). In contrast to HER-2/neu expression, which markedly decreased in the neoepidermis, HER-3 expression was markedly increased in all keratinocytes of the migrating neoepidermis in both control and rhNDF- $\alpha_{2}$-treated wounds (Fig. $7 \mathrm{D}$ ).

NDF as detected by both the $\alpha$ isoform-specific mAb, $1 \mathrm{H} 7 \mathrm{~A}$, and by $1 \mathrm{H} 8 \mathrm{C}$, which detects both $\alpha$ and $\beta$ NDF isoforms, was expressed by dermal fibroblasts within and adjacent to the wound bed (Fig. 7, $E$ and $F$ ). There were no differences in NDF expression in rhNDF- $\alpha_{2}$-treated wounds versus control wounds.

\section{Discussion}

In this study, we have shown that rhNDF- $\alpha_{2}$, but not rhNDF$\alpha_{1}$, rhNDF- $\beta_{1}$, or rhNDF- $\beta_{2}$, accelerates epidermal migration with normal epidermal differentiation but does not induce significant sustained keratinocyte proliferation in rabbit partial thickness excisional wounds. These epidermal effects contrast those described for two other members of the EGF family, EGF and TGF- $\alpha$, both of which induce marked keratinocyte proliferation but do not stimulate normal keratinocyte differentiation $(38,39)$. In addition, both EGF and TGF- $\alpha$ inhibit the growth of hair follicles $(40,41)$, while EGF stimulates the growth of sebaceous (42) and sweat glands (43). In contrast, rhNDF- $\alpha_{2}$ has no apparent effect on any dermal adnexa, both in the rabbit ear excisional wound model and after systemic administration to neonatal rats (Danilenko, D. M., and G. F. Pierce, unpublished data).

The epidermal effects of rhNDF- $\alpha_{2}$ are also in contrast with those induced by other growth factors having paracrine epidermal effects. Keratinocyte growth factor, a member of the fibroblast growth factor family (44), induces marked proliferation but less extensive epidermal migration than does rhNDF- $\alpha_{2}$ (28). Also in contrast with rhNDF- $\alpha_{2}$, keratinocyte growth factor directly stimulates hair follicles and sebaceous glands (28). Other growth factors which have been reported to stimulate wound reepithelialization in vivo are basic fibroblast growth factor (bFGF) and platelet-derived growth factor (PDGF). bFGF directly stimulates keratinocyte growth in vitro (45) and has similar in vivo effects, namely epidermal proliferation and a moderate increase in epidermal migration (27). PDGF does not appear to bind keratinocytes directly (46), but acts on the epidermis indirectly, presumably via the stimulation of dermal fibroblasts to produce paracrine growth factors with epidermal effects (27). In contrast with rhNDF- $\alpha_{2}$, both bFGF and PDGF stimulate epidermal proliferation (27).

TGF- $\beta$ has some effects on the epidermis and keratinocytes which are very similar to those of rhNDF- $\alpha_{2}$. Like rhNDF- $\alpha_{2}$, TGF- $\beta$ does not induce prominent sustained epidermal proliferation and can actually inhibit the growth of cultured keratinocytes in vitro (47). In addition, TGF- $\beta 1$ also appears to increase keratinocyte integrin expression, specifically integrins $\alpha_{5} \beta_{1}$ and $\alpha_{v} \beta_{5}$ (48). Unlike rhNDF- $\alpha_{2}$, however, TGF- $\beta$ decreases the rate of wound reepithelialization in vivo (27) and induces keratinocytes to assume a hyperproliferative phenotype in vitro (47) and to exhibit disorderly keratinization (dyskeratosis) in vivo (26), while rhNDF- $\alpha_{2}$-treated wounds exhibit normal differentiation. Therefore, in contrast with all other currently known 

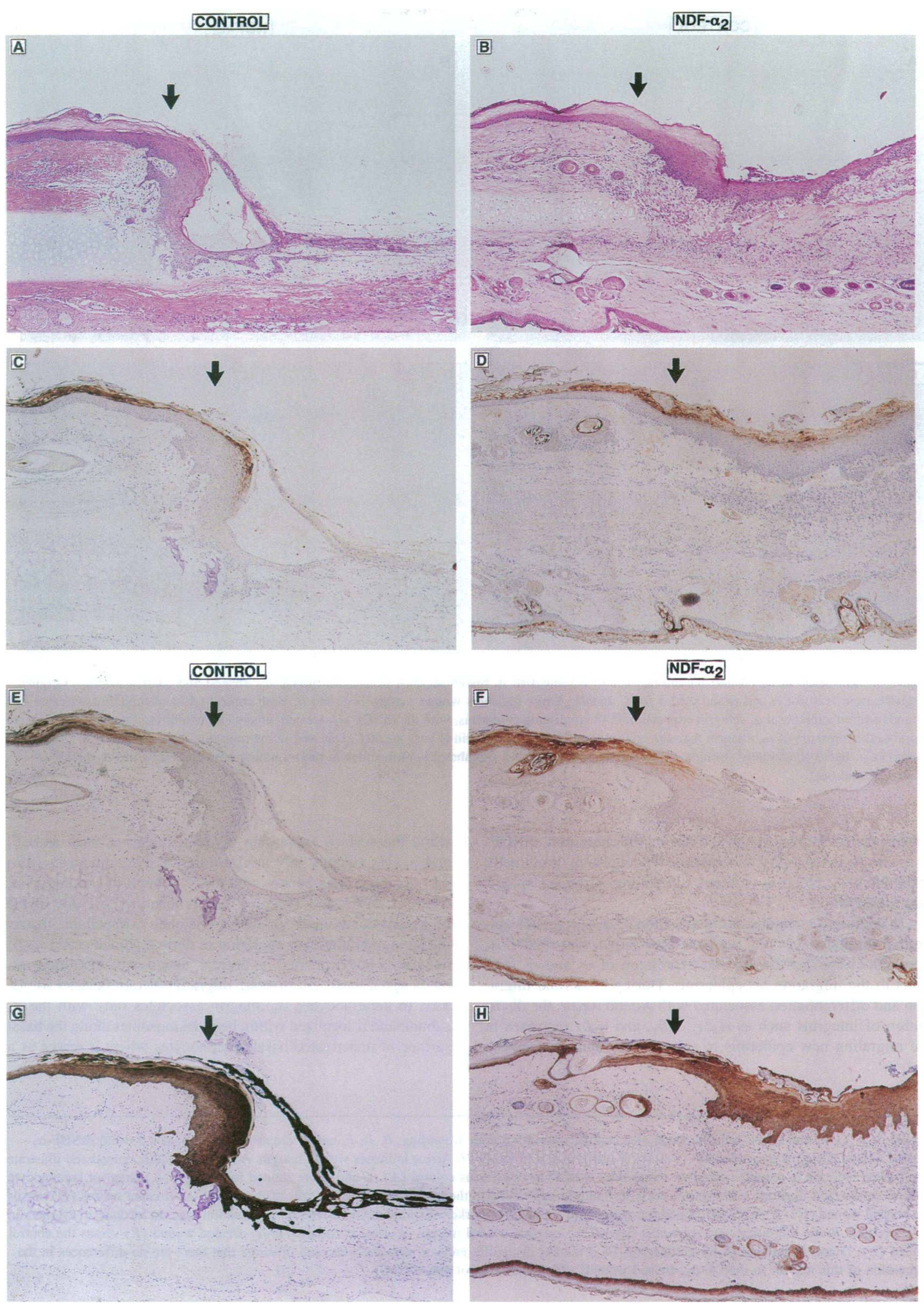

Figure 5. 

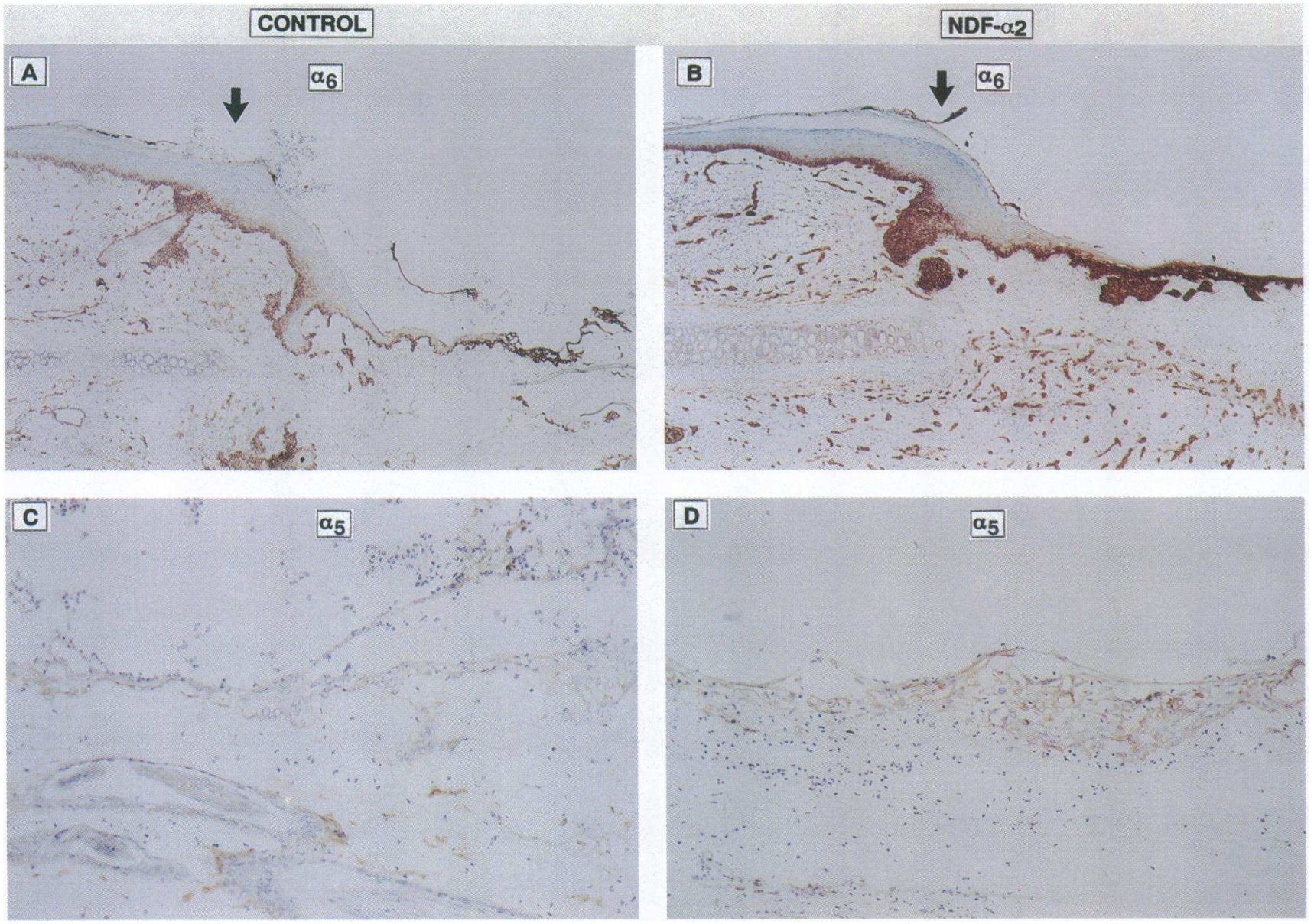

Figure 6. Expression of $\alpha_{6}(A$ and $B)$ and $\alpha_{5}(C$ and $D)$ integrins in frozen sections of 5-d-old rhNDF- $\alpha_{2}-$ treated and control wounds. Original magnification, $\times 20$ for $A$ and $B$ and $\times 62.5$ for $C$ and $D$. Arrow indicates wound margin in $A$ and $B$. Both control $(A)$ and rhNDF- $\alpha_{2}-$ treated $(B)$ wounds exhibit suprabasal $\alpha_{6}$ integrin expression in the migrating epidermis, with the rhNDF- $\alpha_{2}-$ treated wound $(B)$ exhibiting much more extensive suprabasal expression of $\alpha_{6}$ integrin than the control wound $(A) . \alpha_{5}$ integrin is very weakly expressed in the migrating new epidermis of the control wound $(C)$, but is moderately strongly expressed in both basal and suprabasal keratinocytes in the migrating new epidermis of the rhNDF- $\alpha_{2}-$ treated wound $(D)$.

growth factors known to have effects on the epidermis, rhNDF$\alpha_{2}$ is unique in its ability to accelerate the migration of normally differentiated epidermis without stimulating sustained epidermal proliferation.

In addition to demonstrating that rhNDF- $\alpha_{2}$ accelerates epidermal migration in vivo, we have also shown that rhNDF- $\alpha_{2}$ upregulates the distribution and expression of $\alpha_{5}$ and $\alpha_{6}$ integrins in the migrating neoepidermis. During epidermal migration and differentiation associated with wound repair, the distribution of integrins such as $\alpha_{2} \beta_{1}, \alpha_{3} \beta_{1}$, and $\alpha_{6} \beta_{4}$ increases in the migrating new epidermis to extend into suprabasal layers, while the surface expression of other integrins, such as $\alpha_{5} \beta_{1}$ and $\alpha_{\mathrm{v}}$, is markedly increased in migrating keratinocytes (4951 ). $\alpha_{5}$ integrin associates with the $\beta_{1}$ subunit in keratinocytes, where it serves as a receptor for fibronectin (36), one of the important components of the provisional extracellular matrix mediating keratinocyte migration in dermal wounds (52). $\alpha_{5} \beta_{1}$ integrin is not expressed on normal, unactivated keratinocytes, but is upregulated in activated, migrating keratinocytes $(50,51$, 53 ). In keratinocytes, $\alpha_{6}$ integrin associates only with the $\beta_{4}$ subunit and is localized within hemidesmosomes along the basal surface of unactivated basal keratinocytes where it serves as a

Figure 5. $A, C, E$, and $G$ are serial sections of a control wound $5 \mathrm{~d}$ after wounding. $B, D, F$, and $H$ are serial sections of a 5-d-old rhNDF- $\alpha_{2}-$ treated wound. Original magnification, $\times 20$ for $A$ and $B$ and $\times 25$ for $C-H$. Arrow indicates wound margin. $A$ and $B$ are $H \& E$ stained and illustrate the marked increase in reepithelialization induced by rhNDF- $\alpha_{2}(B)$ versus control $(A) . C$ and $D$ are stained for filaggrin, a marker of keratinocyte differentiation, and illustrate a marked increase in filaggrin expression in the migrating new epidermis of the rhNDF- $\alpha_{2}$-treated wound $(D)$ versus the control wound $(C) . E$ and $F$ are stained for cytokeratin 10, another marker of keratinocyte differentiation, and illustrate an increase in cytokeratin 10 expression in the migrating new epidermis beyond the original wound margin (arrow) in the rhNDF- $\alpha_{2}-$ treated wound $(F)$ versus the control wound $(E) . G$ and $H$ are stained for cytokeratin 14, a marker of undifferentiated keratinocytes, and illustrate that there are no differences in the expression of this marker in rhNDF- $\alpha_{2}$-treated wounds $(H)$ versus control wounds $(G)$. 

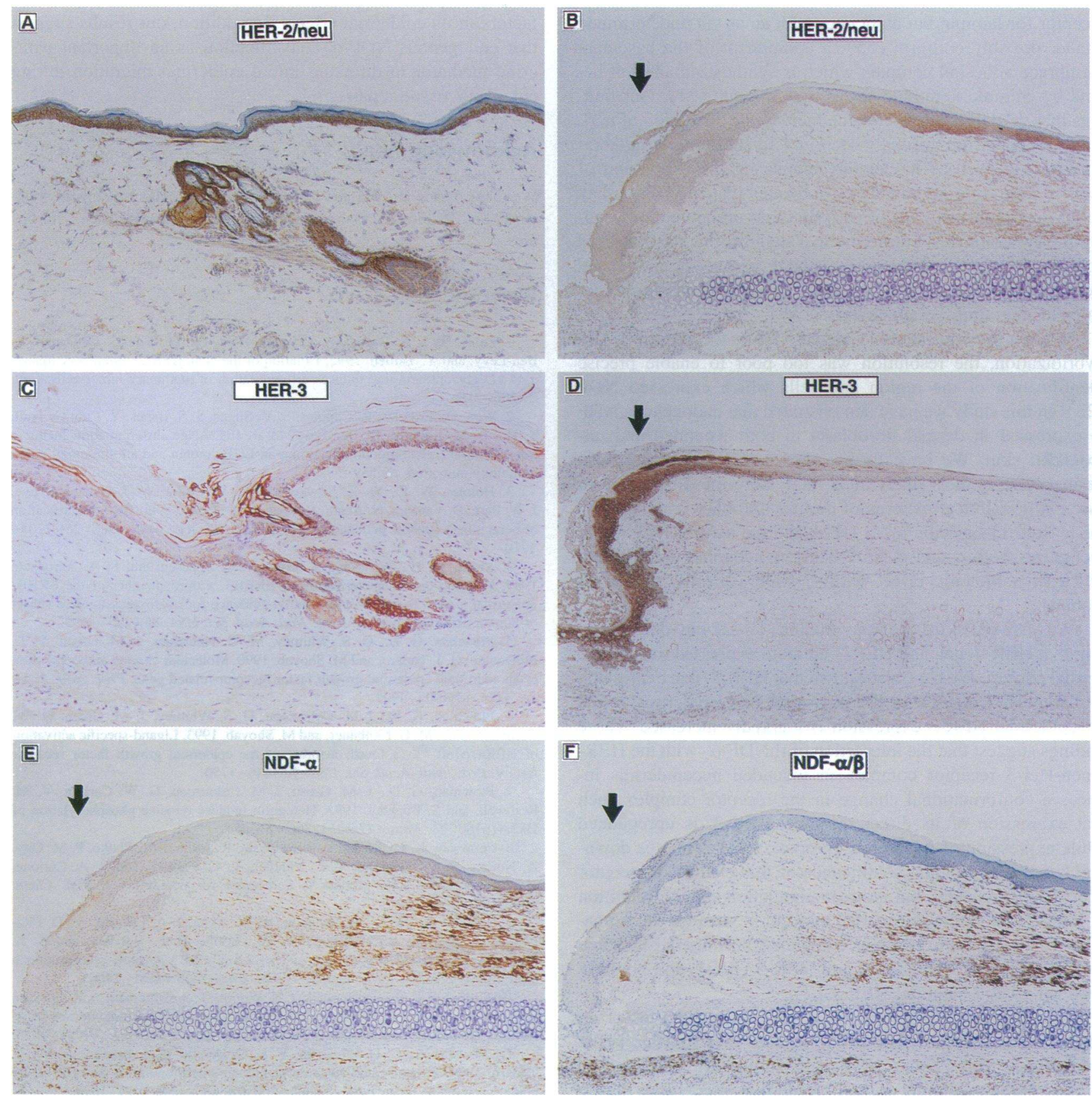

Figure 7. Expression of HER-2/neu; HER-3, and two different epitopes of NDF in sections of rabbit ear. $A$ and $B$ are frozen sections stained for HER-2/neu expression, $C$ and $D$ are fixed sections stained for HER-3 expression, and $E$ and $F$ are frozen sections stained with two different antiNDF mAbs. $B, E$, and $F$ all illustrate the same ear wound. Original magnification, $\times 50$ for $A$ and $C, \times 20$ for $B, D, E$, and $F$. Arrow indicates wound margin. $A$ is normal skin and illustrates that HER-2/neu is expressed in basal and spinous layers of unwounded epidermis as well as in the basal layers of hair follicles and sebaceous glands. $B$ is a wound margin and illustrates a marked decrease in HER-2/neu expression in wound neoepidermis. $C$ is normal skin and illustrates that HER-3 is weakly expressed in unwounded epidermal basal keratinocytes, but is strongly expressed in basal layers of hair follicles and sebaceous glands as well as by follicular keratin. $D$ is a wound margin and illustrates that wound neoepidermis exhibits a marked increase in both intensity and extent of HER-3 expression, in sharp contrast to the decreased neoepidermal expression of HER $2 /$ neu illustrated in $B$ above. $E$ is a wound margin stained with the NDF $\alpha$ isoform-specific mAb, 1H7A, and illustrates that dermal fibroblasts in both wounded and unwounded areas express $\alpha$ NDF isoforms. $F$ is a wound margin stained with the mAb 1H8C, which recognizes both $\alpha$ and $\beta$ isoforms of NDF, and illustrates a pattern of localization virtually identical to that of 1H7A in dermal fibroblasts in both wounded and unwounded areas.

receptor for laminin $(35,54,55)$. In migrating keratinocytes, $\alpha_{6} \beta_{4}$ integrin is one of the first adhesion molecules to appear when keratinocytes associate with connective tissue (55), and its distribution increases to include lateral as well as basal surfaces of all keratinocytes, both basal and suprabasal (49-51). In this activated state, keratinocyte $\alpha_{6} \beta_{4}$ integrin is no longer a 
receptor for laminin but associates with an as yet undetermined ligand, possibly epiligrin (55), a component of the basement membrane adhesion complex which is synthesized and left behind by cultured keratinocytes as they migrate (34). Our findings that rhNDF- $\alpha_{2}$ augments the increased distribution of $\alpha_{6} \beta_{4}$ integrin expression normally seen in activated, migrating keratinocytes, as well as moderately increasing the expression of $\alpha_{5} \beta_{1}$ in migrating keratinocytes, indicates that rhNDF- $\alpha_{2}$ may be an important mediator of early integrin upregulation by migrating keratinocytes. Furthermore, it suggests that the increased epidermal migration induced by rhNDF- $\alpha_{2}$ may be modulated by increased expression of integrins and other adhesion molecules in migrating keratinocytes.

While a previous study localized NDF to the skin by in situ hybridization, the resolution was too poor to enable precise identification of the region and cells which expressed NDF (23). In this study we have demonstrated that endogenous NDF is expressed in dermal fibroblasts in both wounded and unwounded skin. We have further shown that this endogenous dermal NDF is most likely an $\alpha$ NDF isoform(s) by virtue of essentially identical patterns of dermal fibroblast staining with the $\alpha$ isoform-specific mAb $1 \mathrm{H} 7 \mathrm{~A}$ and the mAb $1 \mathrm{H} 8 \mathrm{C}$, which recognizes both $\alpha$ and $\beta$ NDF isoforms, coupled with the absence of a biologic effect with $\beta$ NDF isoforms in dermal wounds.

We have extended previous studies (19-22) by demonstrating that HER-2/neu and HER-3 are both expressed in skin and dermal adnexa. We have also shown that HER-2/neu expression is markedly decreased in the migrating new epidermis, while neoepidermal HER-3 expression is markedly increased. These findings suggest that the interaction of rhNDF- $\alpha_{2}$ with the HER$2 /$ neu-Her-3 receptor complex in wounded neoepidermis induces a conformational change in the receptor complex such that expression of its direct receptor, HER-3, is upregulated while expression of its indirect receptor, HER-2/neu, is downregulated. The biologic significance of this change in receptor expression is unclear, but indirect stimulation and/or inhibition of HER-2/neu has been reported to occur in vitro via the formation of heterodimeric receptor complexes between HER-2/neu and EGFR (56), HER-2/neu and HER-3 $(8,9)$, and possibly between HER-2/neu and HER-4 (7).

The finding that only rhNDF- $\alpha_{2}$ has an in vivo effect on dermal wound reepithelialization suggests that NDF- $\alpha_{2}$ is the predominant endogenous NDF isoform in skin and plays a unique role in mediating dermal-epidermal interactions during cutaneous tissue repair. It further suggests that the different NDF isoforms exhibit different in vivo biologic activities in addition to having differing patterns of cell and tissue distribution. The finding that $\beta$ isoforms of NDF do not appear to have any in vivo biologic activity in cutaneous tissue repair is not altogether unexpected, since these isoforms have been localized primarily to nervous tissue (16). The lack of in vivo biologic activity in our cutaneous tissue repair model with rhNDF- $\alpha_{1}$, however, was somewhat unanticipated and suggests that the differing biologic activities of individual NDF isoforms extend beyond those attributable solely to the differences between $\alpha$ and $\beta$ isoforms. Further studies in different in vivo model systems will be required to more fully delineate the biologic roles of the different NDF isoforms.

In summary, this study is the first report describing an in vivo biologic effect for NDF and demonstrates that NDF, and specifically NDF- $\alpha_{2}$, is unique among currently known growth factors in its epidermal effects. In addition, our results suggest that endogenous NDF- $\alpha_{2}$ may function as an important paracrine mediator in directing initial epidermal migration during cutaneous tissue repair.

\section{Acknowledgments}

We thank Diane Duryea and Carol Burgh for excellent technical assistance, and Jennifer Keysor and Danette Barron for assistance with figures.

\section{References}

1. Peles, E., S. S. Bacus, R. A. Koski, H. S. Lu, D. Wen, S. G. Ogden, R. Ben-Levy, and Y. Yarden. 1992. Isolation of the Neu/HER-2 stimulatory ligand: a $44 \mathrm{kD}$ glycoprotein that induces differentiation of mammary tumor cells. Cell. 69:206-216.

2. Wen, D., E. Peles, R. Cupples, S. V. Suggs, S. S. Bacus, Y. Luo, G. Trail, S. Hu, S. M. Silbiger, R. Ben-Levy, et al. 1992. Neu differentiation factor: a transmembrane glycoprotein containing an EGF domain and an immunoglobulin homology unit. Cell. 69:559-572.

3. Holmes, W. E., M. X. Sliwkowski, R. W. Akita, W. J. Henzel, J. Lee, J. W. Park, D. Yansura, N. Abadi, H. Raab, G. D. Lewis, et al. 1992. Identification of heregulin, a specific activator of p185erbB2. Science (Wash. DC). 256:12051210 .

4. Kraus, M. H., W. Issing, T. Miki, N. C. Popescu, and S. A. Aaronson 1989. Isolation and characterization of ERBB3, a third member of the ERBB/ epidermal growth factor receptor family: evidence for overexpression in a subset of human mammary tumors. Proc. Natl. Acad. Sci. USA. 86:9193-9197.

5. Plowman, G. D., G. S. Whitney, M. G. Neubauer, J. M. Green, V. L. McDonald, G. J. Todaro, and M. Shoyab. 1990. Molecular cloning and expression of an additional epidermal growth factor receptor-related gene. Proc. Natl. Acad. Sci. USA. 87:4905-4909.

6. Plowman, G. D., J.-M. Culouscou, G. S. Whitney, J. M. Green, G. W. Carlton, L. Foy, M. G. Neubauer, and M. Shoyab. 1993. Ligand-specific activation of HER4/p180 ${ }^{\mathrm{erbB}} 4$, a fourth member of the epidermal growth factor receptor family. Proc. Natl. Acad. Sci. USA. 90:1746-1750.

7. Plowman, G. D., J. M. Green, J.-M. Culouscou, G. W. Carlton, V. M Rothwell, and S. Buckley. 1993. Heregulin induces tyrosine phosphorylation of HER4/p180 erbB4. Nature (Lond.). 366:473-475.

8. Carraway, K. L., III, M. X. Sliwkowski, R. Akita, J. V. Platko, P. M. Guy, A. Nuijens, A. J. Diamonti, R. L. Vandlen, L. C. Cantley, and R. A. Cerione. 1994. The erbB3 gene product is a receptor for heregulin. J. Biol. Chem. 269:14303-14306.

9. Sliwkowski, M. X., G. Schaefer, R. W. Akita, J. A. Lofgren, V. D. Fitzpatrick, A. Nuijens, B. M. Fendly, R. A. Cerione, R. L. Vandlen, and K. L. Carraway III. 1994. Coexpression of erbB2 and erbB3 proteins reconstitutes a high affinity receptor for heregulin. J. Biol. Chem. 269:14661-14665.

10. Coffey, R. J., Jr., R. Derynck, J. N. Wilcox, T. S. Bringman, A. S. Goustin, H. L. Moses, and M. R. Pittelkow. 1987. Production and auto-induction of transforming growth factor- $\alpha$ in human keratinocytes. Nature (Lond.). 328:817-820.

11. Shoyab, M., G. D. Plowman, V. L. McDonald, G. J. Bradley, and G. J. Todaro. 1989. Structure and function of human amphiregulin: a member of the epidermal growth factor family. Science (Wash. DC). 243:1074-1076.

12. Higashiyama, S., J. A. Abraham, J. Miller, J. C. Fiddes, and M. Klagsbrun. 1991. A heparin binding growth factor secreted by macrophage-like cells that is related to EGF. Science (Wash. DC). 251:936-939.

13. Yates, R. A., L. B. Nanney, R. E. Gates, and L. E. King. 1991. Epidermal growth factor and related growth factors. Int. J. Dermatol. 30:687-694.

14. Shing, Y., G. Chrostofori, D. Hanahan, Y. Ono, R. Sasada, K. Igarashi, and J. Folkman. 1993. Betacellulin: a mitogen from pancreatic beta cell tumors. Science (Wash. DC). 259:1604-1607.

15. Prigent, S. A., and N. R. Lemoine. 1992. The type 1 (EGFR-related) family of growth factor receptors and their ligands. Prog. Growth Factor Res. $4: 1-24$.

16. Wen, D., S. V. Suggs, D. Karunagaran, N. Liu, R. L. Cupples, Y. Luo, A. M. Janssen, N. Ben-Baruch, D. B. Trollinger, V. L. Jacobsen, et al. 1994. Structural and functional aspects of the multiplicity of neu differentiation factors. Mol. Cell. Biol. 14:1909-1919.

17. Marchionni, M. A., A. D. J. Goodearl, M. S. Chen, O. BerminghamMcDonogh, C. Kirk, M. Hendricks, F. Danehy, D. Misumi, J. Sudhalter, K. Kobayashi, et al. 1993. Glial growth factors are alternatively spliced erbB2 ligands expressed in the nervous system. Nature (Lond.). 362:312-318.

18. Falls, D. L., K. M. Rosen, G. Corfas, W. S. Lane, and G. D. Fishbach. 1993 ARIA, a protein that stimulates acetylcholine receptor synthesis, is a member of the Neu ligand family. Cell. 72:801-815. 
19. Kokai, Y., J. A. Cohen, J. A. Drebin, and M. I. Greene. 1987. Stage- and tissue-specific expression of the neu oncogene in rat development. Proc. Natl. Acad. Sci. USA. 84:8498-8501.

20. Press, M. F., C. Cordon-Cardo, and D. J. Slamon. 1990. Expression of the HER-2/neu proto-oncogene in normal human adult and fetal tissues. Oncogene. 5:953-962.

21. Prigent, S. A., N. R. Lemoine, C. M. Hughes, G. D. Plowman, C. Selden, and W. J. Gullick. 1992. Expression of the c-erbB-3 protein in normal human adult and fetal tissues. Oncogene. 7:1273-1278.

22. Maguire, H. C., C. Jaworsky, J. A. Cohen, M. Hellman, D. B. Weiner, and M. I. Greene. 1989. Distribution of neu (c-erbB-2) protein in human skin. J. Invest. Dermatol. 89:786-790.

23. Orr-Urtreger, A., L. Trakhtenbrot, R. Ben-Levy, D. Wen, G. Rechavi, P. Lonai, and Y. Yarden. 1993. Neural expression and chromosomal mapping of Neu differentiation factor to 8p12-p21. Proc. Natl. Acad. Sci. USA. 90:18671871.

24. Schultz, G. S., M. White, R. Mitchell, G. Brown, J. Lynch, D. R. Twardzik, and G. J. Todaro. 1987. Epithelial wound healing enhanced by transforming growth factor- $\alpha$ and vaccinia growth factor. Science (Wash. DC). 235:350-352.

25. Brown, G. L., L. B. Nanney, J. Griffen, A. B. Cramer, J. M. Yancey, L. J. Curtsinger III, L. Holtzin, G. S. Schultz, M. J. Jurkiewicz, and J. B. Lynch. 1989. Enhancement of wound healing by topical treatment with epidermal growth factor. N. Engl. J. Med. 321:76-79.

26. Lynch, S. E., R. B. Colvin, and H. N. Antoniades. 1989. Growth factors in wound healing. Single and synergistic effects on partial thickness porcine skin wounds. J. Clin. Invest. 84:640-646.

27. Mustoe, T. A., G. F. Pierce, C. Morishima, and T. F. Deuel. 1991. Growth factor-induced acceleration of tissue repair through direct and inductive activities in a rabbit dermal ulcer model. J. Clin. Invest. 87:694-703.

28. Pierce, G. F., D. Yanagihara, K. Klopchin, D. M. Danilenko, E. Hsu, W. C. Kenney, and C. F. Morris. 1994. Stimulation of all epithelial elements during skin regeneration by keratinocyte growth factor. J. Exp. Med. 179:831840 .

29. Brigham-Burke, M., J. R. Edwards, and D. J. O'Shannessy. 1992. Detection of receptor-ligand interactions using surface plasmon resonance: model studies employing the HIV-1 gp 120/CD4 interaction. Anal. Biochem. 267:125-131.

30. Zeder-Lutz, G., D. Altschuh, H. M. Geysen, E. Trifilieff, G. Sommermeyer, and M. H. Van Regenmortel. 1993. Monoclonal antipeptide antibodies: affinity and kinetic rate constants measured for the peptide and the cognate protein using a biosensor technology. Mol. Immunol. 30:145-155.

31. Dale, B. A., K. A. Holbrook, and P. M. Steinert. 1978. Assembly of stratum corneum basic protein and keratin filaments in macrofibrils. Nature (Lond.). 276:729-731

32. Galvin, S., C. Loomis, M. Manabe, D. Dhouailly, and T.-T. Sun. 1989. The major pathways of keratinocyte differentiation as defined by keratin expression: an overview. Advances in Dermatology. 4:277-300.

33. Chen, J. D., J. P. Kim, K. Zhang, Y. Sarret, K. C. Wynn, R. H. Kramer, and D. T. Woodley. 1993. Epidermal growth factor (EGF) promotes human keratinocyte locomotion on collagen by increasing the $\alpha 2$ integrin subunit. $\operatorname{Exp}$. Cell Res. 209:216-223.

34. Carter, W. G., M. C. Ryan, and P. J. Gahr. 1991. Epiligrin, a new cell adhesion ligand for integrin $\alpha_{3} \beta_{1}$ in epithelial basement membranes. Cell. 65:599610.

35. Lee, E. C., M. M. Lotz, G. D. Steele, Jr., and A. M. Mercurio. 1992. The integrin $\alpha 6 \beta 4$ is a laminin receptor. J. Cell Biol. 117:671-678.

36. Adams, J. C., and F. M. Watt. 1990. Changes in keratinocyte adhesion during terminal differentiation: reduction in fibronectin binding precedes $\alpha_{5} \beta_{1}$ integrin loss from the cell surface. Cell. 63:425-435.

37. Carter, W. G., E. A. Wayner, T. S. Bouchard, and P. Kaur. 1990. The role of integrins $\alpha_{2} \beta_{1}$ and $\alpha_{3} \beta_{1}$ in cell-cell and cell-substrate adhesion of human epidermal cells. J. Cell Biol. 110:1387-1404.

38. Marchese, C., J. Rubin, D. Ron, A. Faggioni, M. R. Torrisi, A. Messina, L. Frati, and S. A. Aaronson. 1990. Human keratinocyte growth factor activity on proliferation and differentiation of human keratinocytes: differentiation response distinguishes KGF from EGF family. J. Cell. Physiol. 144:326-332.

39. Jiang, C.-K., T. Magnaldo, M. Ohtsuki, I. M. Freedberg, F. Bernerd, and M. Blumenberg. 1993. Epidermal growth factor and transforming growth factor $\alpha$ specifically induce the activation- and hyperproliferation-associated keratins 6 and 16. Proc. Natl. Acad. Sci. USA. 90:6786-6790.

40. Moore, G. P. M., B. A. Panaretto, and D. Robertson. 1983. Epidermal growth factor delays the development of the epidermis and the hair follicles of mice during growth of the first coat. Anat. Rec. 205:47-55.

41. Tam, J. P. 1985. Physiological effects of transforming growth factor in the newborn mouse. Science (Wash. DC). 229:673-675.

42. Matias, J. R., and N. Orentreich. 1983. Stimulation of hamster sebaceous glands by epidermal growth factor. J. Invest. Dermatol. 80:516-519.

43. Blecher, S. R., J. Kapalanga, and D. Lalonde. 1990. Induction of sweat glands by epidermal growth factor in murine $x$-linked anhidrotic ectodermal dysplasia. Nature (Lond.). 345:542-544.

44. Finch, P. W., J. S. Rubin, T. Miki, D. Ron, and S. A. Aaronson. 1989. Human KGF is FGF-related with properties of a paracrine effector of epithelial cell growth. Science (Wash. DC). 245:752-755.

45. O'Keefe, E. J., M. L. Chiu, and R. E. Payne. 1988. Stimulation of growth of keratinocytes by basic fibroblast growth factor. J. Invest. Dermatol. 90:767769

46. Deuel, T. F. 1987. Polypeptide growth factors: roles in normal and abnormal cell growth. Annu. Rev. Cell Biol. 3:443-492.

47. Choi, Y., and E. Fuchs. 1990. TGF- $\beta$ and retinoic acid: regulators of growth and modifiers of differentiation in human epidermal cells. Cell Regul. 1:791-809.

48. Gailit, J., M. P. Welch, and R. A. F. Clark. 1994. TGF- $\beta$ stimulates expression of keratinocyte integrins during re-epithelialization of cutaneous wounds. J. Invest. Dermatol. 103:221-227.

49. Hertle, M. D., M.-D. Kubler, I. M. Leigh, and F. M. Watt. 1992. Aberrant integrin expression during epidermal wound healing and in psoriatic epidermis. J. Clin. Invest. 89:1892-1901.

50. Juhasz, I., G. F. Murphy, H.-C. Yan, M. Herlyn, and S. M. Albelda. 1993. Regulation of extracellular matrix proteins and integrin cell substratum adhesion receptors on epithelium during cutaneous human wound healing in vivo. Am. J. Pathol. 143:1458-1469.

51. Larjava, H., T. Salo, K. Haapasalmi, R. H. Kramer, and J. Heino. 1993. Expression of integrins and basement membrane components by wound keratinocytes. J. Clin. Invest. 92:1425-1435.

52. Clark, R. A. F., J. M. Lanigan, P. DellaPelle, E. Manseau, H. F. Dvorak, and R. B. Colvin. 1982. Fibronectin and fibrin provide a provisional matrix for epidermal cell migration during wound reepithelialization. J. Invest. Dermatol. 79:264-269.

53. Guo, M., L. T. Kim, S. K. Akiyama, H. R. Gralnick, K. M. Yamada, and F. Grinnell. 1991. Altered processing of integrin receptors during keratinocyte activation. Exp. Cell Res. 195:315-322.

54. Stepp, M. A., S. Spurr-Michaud, A. Tisdale, J. Elwell, and I. K. Gipson. 1990. $\alpha 6 \beta 4$ integrin heterodimer is a component of hemidesmosomes. Proc. Natl. Acad. Sci. USA. 87:8970-8974.

55. Kurpakus, M. A., V. Quaranta, and J. C. R. Jones. 1991. Surface relocation of alpha beta $_{4}$ integrins and assembly of hemidesmosomes in an in vitro model of wound healing. J. Cell Biol. 115:1737-1750.

56. Spivak-Kroizman, T., D. Rotin, D. Pinchasi, A. Ullrich, J. Schlessinger and I. Lax. 1992. Heterodimerization of c-erbB2 with different epidermal growth factor receptor mutants elicits stimulatory or inhibitory responses. J. Biol. Chem. 267:8056-8063. 